\title{
Pilot Randomized Controlled Trial of Inhaled Milrinone in High-Risk Cardiac Surgical Patients
}

André Y. Denault ${ }^{*}$ François Haddad $^{2}$, Yoan Lamarche ${ }^{3}$ Anne Q.N. Nguyen ${ }^{4}$, France Varin ${ }^{4}$, Sylvie Levesque ${ }^{5}$,Yanfen Shi ${ }^{2}$, Louis P. Perrault $^{3}$, Jean-Claude Tardif ${ }^{2}$ and Jean Lambert ${ }^{5}$

${ }^{1}$ Departments of Anesthesia, Montreal Heart Institute, Montreal, Quebec, Canada ${ }^{2}$ Departments of Medicine, Montreal Heart Institute, Montreal, Quebec, Canada

${ }^{3}$ Departments of Cardiac Surgery, Montreal Heart Institute, Montreal, Quebec, Canada

${ }^{4}$ Department of Pharmacology, Université de Montréal, Montreal, Quebec, Canada

${ }^{5}$ Montreal Heart Institute Coordinating Center (MHICC), Montreal, Quebec, Canada

\begin{abstract}
Background: Pulmonary hypertension is a major cause of mortality and morbidity in patients undergoing valvular and complex heart surgery. Inhaled milrinone has been used for the treatment of pulmonary hypertension, but its safety and effects compared with a placebo on hemodynamics and ventricular function have not been studied in patients undergoing high-risk valvular surgery.
\end{abstract}

Methods: Twenty-one high-risk cardiac surgical patients with preoperative pulmonary hypertension were randomized in a double-blind study to receive inhaled milrinone or placebo. The inhalation occurred after the induction of anesthesia and before the surgical incision and cardiopulmonary bypass. The effects on ventricular function were evaluated by means of pulmonary artery catheterization and transesophageal echocardiography. The primary outcome variable was the systemic mean arterial pressure.

Results: There were 8 men and 13 women (mean age $71 \pm 6$ years) with a mean Parsonnet score of $32 \pm 9$ who underwent a total of 17 complex procedures and 6 reoperations. There were no significant changes in mean arterial pressure throughout the study. A reduction in pulmonary vascular resistance $(p=0.0458)$ was observed in the inhaled milrinone group, but the change in mean pulmonary artery pressure was not significant $(p=0.1655)$. Right ventricular end-diastolic area $(p=0.0363)$ and right atrial transverse diameter $(p<0.0001)$ increased in the control group, but not with inhaled milrinone. No significant side effects occurred in the inhaled milrinone group.

Conclusion: In this high-risk cardiac surgery cohort, the use of inhaled milrinone was not associated with systemic hypotension but with a reduced pulmonary vascular resistance and prevention of the increase in right-sided cavity dimensions.

Keywords: Cardiac surgery; Milrinone; Transesophageal echocardiography; Cardiopulmonary bypass; Outcome; Pulmonary hypertension

\section{Introduction}

Pulmonary hypertension is a major cause of mortality and morbidity in patients undergoing cardiac surgery [1] Several conditions increase the risk of developing perioperative pulmonary hypertension, including pre-existing pulmonary hypertension, mitral stenosis or regurgitation, left ventricular (LV) dysfunction pulmonary disease and cardiopulmonary bypass (CPB) [2]. Studies have suggested that milrinone may be beneficial in the treatment of pulmonary hypertension in cardiac surgery $[3,4]$. However, intravenous milrinone can be associated with systemic hypotension, [5] increased vasoactive drug requirements [6], morbidity [7] and mortality in ischemic cardiomyopathy [8]

The use of the inhaled route for milrinone (iMil) has been described in several animal [9-15], human studies [16-22] and case reports [2326]. As an alternative to inhaled nitric oxide and inhaled prostacyclin, inhaled milrinone (iMil) is also less expensive and does not require a complex set-up and monitoring of toxic metabolites. Furthermore, iMil is readily available in operating rooms and needs no special preparation, as opposed to inhaled prostacyclin. In addition, iMil before CPB has been shown to be superior to an intravenous administration in reducing the pulmonary reperfusion syndrome [10], preventing pulmonary arterial endothelial dysfunction $[12,13]$ and improving oxygenation in a porcine model [10]. Only two open-label studies described the use of iMil after cardiac surgery and in heart transplant candidates undergoing catheterization $[16,17]$, with no significant side effects.

However, in these studies, the timing of administration was constant, the effect on ventricular function using combined hemodynamic and echocardiographic monitoring not evaluated and the investigators were not blind to the effect of iMil. The primary hypothesis of our study was that the administration of milrinone through nebulization before CPB would not be associated with significant systemic hypotension. Our secondary hypothesis was that iMil administered before CPB is better than placebo in improving pulmonary hemodynamics and both LV and right ventricular (RV) function.

\section{Methods}

\section{Study Population}

After approval by our local research and ethics committees and with permission from Health Canada, informed consent was obtained from 22 patients with pulmonary hypertension undergoing cardiac surgery with CPB. Patients were considered to have pulmonary hypertension if the systolic pulmonary artery pressure (SPAP) was greater than 30 $\mathrm{mmHg}$ or the mean pulmonary artery pressure (MPAP) above 25

*Corresponding author: André $Y$. Denault, MD, Montreal Heart Institute, 5000 Bélanger Street, Montreal, Quebec H1T 1Y8, Canada. Tel : (514) 376-3330 ext. 3732; Fax: (514) 376-8784. E-mail: denault@videotron.ca

Received January 03, 2014; Accepted April 17, 2014; Published April 19, 2014

Citation: Denault AY, Haddad F, Lamarche Y, Nguyen AQN, Varin F, et al. (2014) Pilot Randomized Controlled Trial of Inhaled Milrinone in High-Risk Cardiac Surgical Patients. Surgery Curr Res 4: 192. doi:10.4172/2161-1076.1000192

Copyright: (c) 2014 Denault AY, et al. This is an open-access article distributed under the terms of the Creative Commons Attribution License, which permits unrestricted use, distribution, and reproduction in any medium, provided the original author and source are credited. 
$\mathrm{mmHg}$, as measured during the preoperative period or estimated by using Doppler echocardiography. This was confirmed after insertion of a pulmonary artery catheter and before induction of general anesthesia. Patients with severe LV dysfunction (LV ejection fraction of less than $30 \%$ ) were excluded. Other exclusion criteria were the presence of contraindications to transesophageal echocardiography (TEE), including esophageal disease or unstable cervical spine.

\section{Treatment Protocol}

Patients were premedicated with 1 to 2 mg oflorazepam administered orally 1 hour before the operation, as well as $0.1 \mathrm{mg} / \mathrm{kg}$ of morphine administered intramuscularly before being taken to the operating room. Additional midazolam was administered $(0.01-0.05 \mathrm{mg} / \mathrm{kg}$ intravenously) in the operating room as needed for patient comfort. Usual monitoring was installed, including a 5-lead electrocardiogram, pulse oximeter, peripheral venous line, radial arterial line, a $15-\mathrm{cm}$ 3-lumen catheter (CS-12703, Arrow International Inc., Reading, $\mathrm{CA}$ ), and thermodilution pulmonary artery catheter (Swan-Ganz catheter 7.5F; Baxter Healthcare Corporation, Irvine, CA). Anesthesia was induced with $0.04 \mathrm{mg} / \mathrm{kg}$ midazolam and $1 \mu \mathrm{g} / \mathrm{kg}$ sufentanil, and muscle relaxation was achieved with $0.1 \mathrm{mg} / \mathrm{kg}$ pancuronium. After tracheal intubation, anesthesia was maintained with $1 \mu \mathrm{g} / \mathrm{kg} / \mathrm{hr}$ sufentanil and $0.04 \mathrm{mg} / \mathrm{kg} / \mathrm{hr}$ midazolam. No anesthetic gases were used for the induction. Minute ventilation was adjusted to maintain end-tidal carbon dioxide between 30 and $40 \mathrm{mmHg}$ with an infrared carbon dioxide analyzer. Transesophageal echocardiography (Vivid 7 imaging system, GE Healthcare, Amersham, Sweden) was performed after induction of general anesthesia. Intravenous fluids $(0.9 \%$ normal saline) were administered according to estimated insensible losses of $7 \mathrm{ml} / \mathrm{kg} / \mathrm{hr}$ during the surgery and titrated according to blood pressure and central venous pressure (CVP). A decrease in mean arterial pressure (MAP) below $60 \mathrm{mmHg}$ was treated by fluids administration in the presence of a low CVP or by the use of vasopressors according to a predetermined protocol [27]. In case of low cardiac output (CO) with reduced contractility documented using TEE, the anesthesiologist could use intravenous milrinone at his discretion. Postoperative management in case of pulmonary hypertension included intravenous nitroglycerin and milrinone and, in more severe cases, inhaled nitric oxide or inhaled prostacyclin. During CPB, blood cardioplegia was used in all patients. Induction and maintenance of cardioplegia were cold to tepid ( 15 to $29^{\circ}$ Celsius). The blood to crystalloid ratio was $4: 1$. The pump flow was adjusted to obtain an output of $2.2 \mathrm{~L} / \mathrm{min} / \mathrm{m}^{2}$ of body surface area. The pump flow was reduced to $0.5 \mathrm{~L} / \mathrm{min}$ for aortic clamping and unclamping. The pumps used for all patients were SIII (Stockert, Munchen, Germany) roller pumps and the oxygenators were Sorin Monolyth (Mirandola, MO, Italy). For coronary artery bypass procedures, temperature was allowed to drift to $34^{\circ} \mathrm{C}$. Valve and complex procedures were done with temperatures of $32-34^{\circ} \mathrm{C}$. Selective antegrade and retrograde cerebral perfusion were used on a case by case basis. Weaning from CPB was attempted after systemic temperature (central and vesical) was $>36^{\circ} \mathrm{C}$ using a predetermined protocol [27].

\section{Drug Administration Protocol}

Randomization was done according to a list of computerized random numbers generated by the Montreal Heart Institute Coordinating Center and assignment to study treatment was directly transmitted to the pharmacist the day before the surgery. The investigator had no access to the randomization list. The study drug was prepared by the pharmacist and delivered to the operating room wrapped up in an opaque paper to maintain blinding. Patients were equally divided into 2 groups to receive either iMil or placebo in a double-blind randomized manner. Inhaled milrinone (Primacor, Sanofi-Synthelabo Canada Inc., Markham, ON, Canada) or the placebo ( $0.9 \%$ saline) were administered through the endotracheal tube after the induction of anesthesia once baseline hemodynamic profiles and TEE exam were completed [28]. Five milligrams $(1 \mathrm{mg} / \mathrm{mL})$ were administered, resulting in a dose ranging from $50-80 \mu \mathrm{g} / \mathrm{kg}$, over 5 minutes. The study drug and the placebo were administered through a jet nebulizer (Ref 8901; Salter Labs, Arvin, CA) attached to the inspiratory limb of the ventilator near the endotracheal tube with a bypass flow of oxygen at $10 \mathrm{~L} / \mathrm{min}$, as previously described [28].

\section{Data Collection}

At the time of randomization, demographic, diagnostic (New York Heart Association (NYHA) class, Parsonnet score, comorbidities, LV ejection fraction) and therapeutic (medication, type of surgery, reoperations) information was obtained for every patient. Complex surgery was defined as a combination of valve or aortic surgery and coronary procedure or reoperative surgery. Hemodynamic values were indexed for patient body surface area and obtained in the awake state before induction of anesthesia to confirm the presence of pulmonary hypertension, after induction of anesthesia (baseline or T1), at the end of nebulization (T2), 20 minutes after the end of nebulization before CPB (T3) and after CPB during chest closure (T4). The measured hemodynamic parameters included heart rate (HR), systemic arterial pressure (SAP), MAP, CVP, pulmonary capillary wedge pressure (PCWP), SPAP, MPAP and diastolic pulmonary artery pressure (DPAP). Systemic vascular resistance (SVR) and pulmonary vascular resistance (PVR) was calculated using the standard formula. Cardiac output was assessed by using the thermodilution technique with 3 injections of room temperature dextrose $5 \%(10 \mathrm{~mL})$ at end-expiration. All TEE were performed by 2 anesthesiologists with more than 15 years of experience and with National Board Certification. All TEE exams were reviewed offline by a cardiologist expert in echocardiography who was blinded to the allocation group. The exam was obtained after induction (T1), at the end of nebulization (T2), before CPB (T3) and after CPB (T4). The TEE examination included a mid-esophageal, 4-chamber view, a shortaxis transgastric view at the mid-papillary level, and color flow Doppler imaging of all the valves to detect any unsuspected significant valvular disease. All 2-dimensional images in which the LV and RV endocardial border could not be traced adequately by using Schnittger criteria [29] were excluded. The RV function was evaluated using the 4-chamber view according to published guidelines [30]. The following measures were also obtained from the 4-chamber view: the maximal transverse dimensions of the right atrium (RADt) and left atrium (LADt), the right ventricular end-diastolic area (RVEDA), right ventricular endsystolic area (RVESA), the RV fractional area change (RVFAC) in \% calculated as (RVEDA-RVESA)/RVEDA and the tricuspid systolic annular plane excursion (TAPSE). The LV function was evaluated using the 4-chamber view and the transgastric short-axis view. LV end-diastolic area (LVEDA), LV end-systolic area (LVESA) and the LV fractional area change (LVFAC) in \% calculated as (LVEDA - LVESA)/ LVEDA were obtained from both views. Measures were averaged over three consecutive cycles and standardized to end-expiration. The interobserver variability for area measurements was $2.9 \pm 2.0 \%$ (absolute difference) with an intra-class correlation coefficient of 0.95 .

\section{Outcome Measures}

The primary outcome measure was the change in MAP. Secondary outcomes were the changes in MPAP, PVR and PVR/SVR reduction, RV and $L V$ areas. We were also interested in exploring the impact of iMil on weaning from $\mathrm{CPB}$ support, vasopressors use $>24$ hours, postoperative 
atrial fibrillation, intensive care unit (ICU) and hospital stays and mortality. Difficult separation from bypass was defined as SAP $<80$ $\mathrm{mmHg}$, confirmed by central measurement (femoral or aortic); DPAP or PCWP > $15 \mathrm{mmHg}$ during progressive weaning from $\mathrm{CPB}$; and the use of inotropic or vasopressive support (norepinephrine $>4 \mu \mathrm{g} / \mathrm{min}$, epinephrine $>2 \mu \mathrm{g} / \mathrm{min}$, dobutamine $>2 \mu \mathrm{g} / \mathrm{kg} / \mathrm{min}$ ) for at least 1 hour, intra-aortic balloon pump (IABP) requirement or reinitiation of $\mathrm{CPB}$ $[28,31]$.

\section{Statistical Analysis}

Patient characteristics were expressed as mean \pm standard error (SE) or simple frequencies and percentages. Comparisons of continuous variables between groups were performed with the Student $t$-test for normally distributed variables (original or after appropriate transformations) or with the Wilcoxon test for nonnormally distributed variables. Due to very low power, categorical variables were not compared between or within groups. One-way analysis of variance (ANOVA) on repeated measurements were used to study variations over time within each groups. Two-way analysis of co-variance (ANCOVA) adjusted for baseline values (T1) were used to compare groups at T2, T3 and T4. Sample size was calculated for a power of $80 \%$ and a 1 -sided $\alpha$ error value of 0.05 . Assuming a MAP of $75 \mathrm{mmHg}$ in the placebo group, a common standard deviation of 13 $\mathrm{mmHg}, 11$ patients per group would be sufficient to detect a $15 \mathrm{mmHg}$ reduction in MAP in the iMil group. Statistical analyses were done with the computer software SAS version 9.1 (SAS Institute Inc., Cary, NC). A $P$ value $<0.05$ was considered statistically significant.

\section{Results}

A total of 22 patients were recruited over a ten month period. One patient was excluded because the pulmonary artery catheter did not confirm the presence of pulmonary hypertension; therefore, a total of 10 controls and 11 iMil were studied. Patients' characteristics for each group are listed in Table 1. For all patients, the mean age was $71 \pm 6$ years and there were 8 men and 13 women with a mean Parsonnet score of $32 \pm 9$. A total of 17 complex procedures and 6 reoperations were performed. The pre-induction hemodynamic variables (not shown) were similar between the groups for the HR, SAP, MAP, CVP, PCWP

\begin{tabular}{|c|c|c|}
\hline Characteristics & $\begin{array}{l}\text { Control } \\
(n=10)\end{array}$ & $\begin{array}{l}\text { Inhaled Milrinone } \\
\quad(n=11)\end{array}$ \\
\hline Age (yrs) & $71 \pm 1$ & $70 \pm 3$ \\
\hline $\begin{array}{l}\text { Sex } \\
\text { Male }\end{array}$ & $3(30 \%)$ & $5(45 \%)$ \\
\hline BMI $\left(\mathrm{kg} / \mathrm{m}^{2}\right)$ & $27 \pm 2$ & $26 \pm 1$ \\
\hline $\begin{array}{c}\text { NYHA class } \\
1 \\
2 \\
3 \\
4\end{array}$ & $\begin{array}{c}0 \\
2(20 \%) \\
8(80 \%) \\
0\end{array}$ & $\begin{array}{c}0 \\
0 \\
10(91 \%) \\
1(9 \%)\end{array}$ \\
\hline Parsonnet score & $32 \pm 3$ & $32 \pm 3$ \\
\hline Current smoking & $2(20 \%)$ & 0 \\
\hline $\begin{array}{l}\text { Type of surgery } \\
\text { Isolated valve } \\
\text { Multiple valves } \\
\text { Complex } \\
\text { Other } \\
\text { Reoperations }\end{array}$ & $\begin{array}{c}4(40 \%) \\
0 \\
5(50 \%) \\
1(10 \%) \\
2(20 \%)\end{array}$ & $\begin{array}{c}0 \\
4(36 \%) \\
6(54 \%) \\
1(9 \%) \\
4(36 \%)\end{array}$ \\
\hline $\begin{array}{l}\text { Cardiac disease } \\
\text { Prior myocardial infarction } \\
\text { Congestive heart failure }\end{array}$ & $\begin{array}{l}1(10 \%) \\
8(80 \%)\end{array}$ & $\begin{array}{l}2(18 \%) \\
9(82 \%)\end{array}$ \\
\hline $\begin{array}{l}\text { Comorbidities } \\
\text { Hypertension } \\
\text { Diabetes mellitus } \\
\text { Peripheral vascular disease } \\
\text { Renal failure } \\
\text { COPD } \\
\text { Coronary artery disease } \\
\end{array}$ & $\begin{array}{l}7(70 \%) \\
4(40 \%) \\
5(50 \%) \\
3(30 \%) \\
3(30 \%) \\
6(60 \%)\end{array}$ & $\begin{array}{l}7(64 \%) \\
5(45 \%) \\
0 \\
3(27 \%) \\
2(18 \%) \\
4(36 \%)\end{array}$ \\
\hline $\begin{array}{l}\text { Drug therapy at admission } \\
\text { Coumadin } \\
\text { Heparin } \\
\text { Nitrates } \\
\text { Calcium-channel antagonists } \\
\text { Beta-blockers } \\
\text { ACE inhibitors } \\
\text { Digoxin } \\
\text { Diuretics } \\
\text { Salicylates } \\
\text { Statins }\end{array}$ & $\begin{array}{l}4(40 \%) \\
2(20 \%) \\
0 \\
2(20 \%) \\
7(70 \%) \\
4(40 \%) \\
3(30 \%) \\
6(60 \%) \\
3(30 \%) \\
7(70 \%)\end{array}$ & $\begin{array}{l}5(45 \%) \\
1(9 \%) \\
1(9 \%) \\
2(18 \%) \\
5(45 \%) \\
4(36 \%) \\
2(18 \%) \\
3(27 \%) \\
4(36 \%) \\
4(36 \%)\end{array}$ \\
\hline Left ventricular ejection fraction (\%) & $55(50-60)^{*}$ & $58(40-65)^{\star}$ \\
\hline $\begin{array}{l}\text { Duration of surgery }(\mathrm{min}) \\
\text { CPB } \\
\text { Aorta clamping }\end{array}$ & $\begin{array}{l}119 \pm 13 \\
88 \pm 10\end{array}$ & $\begin{array}{c}123 \pm 7 \\
97 \pm 9\end{array}$ \\
\hline
\end{tabular}

Table 1: Baseline Characteristics of the Study Population

ASD, atrial septal defect; AVR, aortic valve replacement; ACE, angiotensin-converting enzyme; BMI, body mass index; CABG, coronary artery bypass graft; CPB, cardiopulmonary bypass; COPD, chronic obstructive pulmonary disease; MV, mitral valve; MVR, mitral valve replacement; NYHA, New York Heart Association; TV, tricuspid valve. ${ }^{*} 1^{\text {st }}$ and $3^{\text {rd }}$ interquartile range. 
Citation: Denault AY, Haddad F, Lamarche Y, Nguyen AQN, Varin F, et al. (2014) Pilot Randomized Controlled Trial of Inhaled Milrinone in High-Risk Cardiac Surgical Patients. Surgery Curr Res 4: 192. doi:10.4172/2161-1076.1000192

Page 4 of 8

and CO. Before the induction of anesthesia, the SPAP $(66 \pm 20$ vs. $46 \pm 13 \mathrm{mmHg}, p=0.0121)$ and MPAP $(45.5 \pm 12$ vs. $33 \pm 8 \mathrm{mmHg}$, $p=0.0047)$ were higher in the iMil group compared to the control group.

\section{Within Groups Comparison}

Hemodynamic Measurements: Hemodynamic evolutions are shown in table 2 for the control and iMil separately. There were no changes over time for MAP in the iMil group $(p=0.3781)$ and in the control group $(p=0.9478)$. In patients receiving iMil, there were changes over time for HR $(p=0.0174)$ and SVR $(p=0.0465)$.

Echocardiographic Measurements: Sequential echocardiographic changes are shown in Erreur! Source du renvoi introuvable. Figure 1 for the control and iMil groups separately. A total of 66 (83\%) 4-chamber views for RV area were analyzed; 58 (73\%) 4-chamber views and 49 (61\%) transgastric views were used for LV area measurements. No changes over time were observed in the iMil group (data not shown). However, changes over time were observed in the control group for RVEDA $(p=0.0363)$, RADt $(p<0.0001)$ and TAPSE $(p=0.0167)$

\section{Between Groups Comparison}

Between groups comparisons are depicted in Table 3 where only variables with significant differences are presented.

Hemodynamic Measurements: Groups were similar at T2 for all variables. However at T3, the means of the iMil group were higher for PCWP $(p=0.0182)$ and DPAP $(p=0.0479)$ and lower for PVR/ SVR ( $p=0.0043)$ as compared to the placebo group, but all of these differences vanished at $\mathrm{T} 4$. The only significant result at $\mathrm{T} 4$ was for $\mathrm{CO}$, which had a lower mean in the iMil group $(p=0.0445)$.

Echocardiographic Measurements: As depicted in 3, the RVEDA and RVESA were different between groups. While the RVEDA mean was lower in the iMil group at T4 $(p=0.0023)$, the RVESA mean was higher in the iMil group at T2 $(p=0.0361)$. Also at T2, the means of the iMil group were higher for RADt $(p=0.0367)$ and lower for RVFAC $(p=0.0366)$. Finally, the only significant result at T3 was for LVESA with a higher mean in the iMil group $(p=0.0106)$.

The outcome and safety data are presented in Table 4 . Because of the small number of patients, no statistical analysis was performed.

\begin{tabular}{|c|c|c|c|c|c|c|}
\hline Variables* & Group & $\begin{array}{c}\mathrm{T1} \\
\text { (Baseline) }\end{array}$ & $\begin{array}{c}\text { T2 } \\
\text { (End Nebulization) }\end{array}$ & $\begin{array}{c}\mathrm{T3} \\
\text { (20 minutes) }\end{array}$ & $\begin{array}{c}\text { T4 } \\
\text { (After CPB) }\end{array}$ & $P$ value \\
\hline \multirow[t]{2}{*}{ HR (beats/min) } & Control & $70.2 \pm 4.4$ & $67.5 \pm 4.0$ & $64.6 \pm 3.1$ & $77.3 \pm 3.6$ & 0.1035 \\
\hline & Inhaled Milrinone & $63.9 \pm 3.6$ & $59.3 \pm 3.6$ & $65.6 \pm 4.3$ & $72.1 \pm 2.4$ & $0.0174^{1}$ \\
\hline \multirow[t]{2}{*}{$\mathrm{SAP}(\mathrm{mmHg})$} & Control & $109.1 \pm 7.5$ & $109.8 \pm 5.7$ & $106.2 \pm 2.2$ & $111.3 \pm 4.8$ & 0.8375 \\
\hline & Inhaled Milrinone & $114.3 \pm 3.7$ & $105.5 \pm 9.0$ & $106.2 \pm 5.8$ & $105.4 \pm 5.6$ & 0.2976 \\
\hline \multirow[t]{2}{*}{$\operatorname{MAP}(\mathrm{mmHg})$} & Control & $73.4 \pm 4.1$ & $74.2 \pm 3.4$ & $71.9 \pm 3.4$ & $71.9 \pm 2.8$ & 0.9478 \\
\hline & Inhaled Milrinone & $78.7 \pm 4.3$ & $75.2 \pm 3.9$ & $71.6 \pm 4.0$ & $72.4 \pm 3.9$ & 0.3781 \\
\hline \multirow[t]{2}{*}{$\mathrm{CVP}(\mathrm{mm} \mathrm{Hg})$} & Control & $10.1 \pm 0.7$ & $11.0 \pm 1.2$ & $10.9 \pm 1.2$ & $14.2 \pm 2.0$ & $0.0157^{2}$ \\
\hline & Inhaled Milrinone & $12.7 \pm 1.4$ & $11.3 \pm 1.6$ & $13.0 \pm 1.6$ & $14.7 \pm 1.6$ & 0.2757 \\
\hline \multirow[t]{2}{*}{ PCWP $(\mathrm{mmHg})$} & Control & $21.9 \pm 1.6$ & $20.3 \pm 1.3$ & $15.8 \pm 1.7$ & $21.5 \pm 2.0$ & 0.0632 \\
\hline & Inhaled Milrinone & $24.2 \pm 3.0$ & $24.1 \pm 2.1$ & $23.5 \pm 2.2$ & $24.1 \pm 2.8$ & 0.8942 \\
\hline \multirow[t]{2}{*}{ SPAP $(\mathrm{mmHg})$} & Control & $37.2 \pm 3.6$ & $39.4 \pm 2.9$ & $36.5 \pm 3.0$ & $39.3 \pm 4.9$ & $0.0147^{3}$ \\
\hline & Inhaled Milrinone & $54.6 \pm 7.0$ & $49.6 \pm 4.8$ & $50.2 \pm 7.8$ & $47.0 \pm 4.2$ & 0.1338 \\
\hline \multirow[t]{2}{*}{ DPAP $(\mathrm{mmHg})$} & Control & $20.7 \pm 1.8$ & $21.7 \pm 1.6$ & $19.5 \pm 1.3$ & $22.0 \pm 2.5$ & $0.0207^{4}$ \\
\hline & Inhaled Milrinone & $26.2 \pm 1.9$ & $24.9 \pm 1.7$ & $26.0 \pm 2.4$ & $28.6 \pm 4.7$ & 0.5694 \\
\hline \multirow[t]{2}{*}{ MPAP $(\mathrm{mmHg})$} & Control & $27.7 \pm 2.5$ & $29.3 \pm 2.1$ & $27.8 \pm 2.3$ & $29.1 \pm 3.4$ & 0.3788 \\
\hline & Inhaled Milrinone & $38.1 \pm 3.9$ & $34.7 \pm 3.0$ & $36.1 \pm 4.5$ & $33.9 \pm 2.3$ & 0.1655 \\
\hline \multirow[t]{2}{*}{$\mathrm{CO}$ (L/min) } & Control & $3.1 \pm 0.3$ & $3.3 \pm 0.3$ & $3.0 \pm 0.3$ & $4.6 \pm 0.3$ & $<0.0001^{5}$ \\
\hline & Inhaled Milrinone & $3.5 \pm 0.3$ & $3.5 \pm 0.3$ & $3.7 \pm 0.3$ & $3.8 \pm 0.1$ & 0.1150 \\
\hline \multirow[t]{2}{*}{ SVR (dynes.sec.cm-5) } & Control & $1737.7 \pm 170.9$ & $1733.1 \pm 181.3$ & $1836.3 \pm 249.6$ & $1064.1 \pm 80.0$ & 0.0542 \\
\hline & Inhaled Milrinone & $1647.5 \pm 176.5$ & $1541.4 \pm 181.7$ & $1347.8 \pm 134.7$ & $1106.4 \pm 80.8$ & $0.0465^{6}$ \\
\hline \multirow[t]{2}{*}{ PVR (dynes.sec.cm-5) } & Control & $149.4 \pm 26.7$ & $216.9 \pm 30.7$ & $295.3 \pm 41.7$ & $134.0 \pm 35.4$ & $0.0376^{7}$ \\
\hline & Inhaled Milrinone & $326.0 \pm 35.0$ & $265.1 \pm 30.6$ & $253.6 \pm 45.5$ & $164.8 \pm 25.9$ & $0.0458^{8}$ \\
\hline \multirow[t]{2}{*}{ PVR/SVR (\%) } & Control & $9.1 \pm 1.3$ & $12.9 \pm 2.8$ & $16.7 \pm 2.2$ & $11.6 \pm 2.7$ & 0.1292 \\
\hline & Inhaled Milrinone & $20.7 \pm 1.6$ & $18.9 \pm 3.1$ & $20.9 \pm 4.2$ & $15.4 \pm 2.4$ & 0.2585 \\
\hline
\end{tabular}

Table 2: Hemodynamic variables: one-way repeated ANOVA

*Variables expressed as adjusted mean \pm standard error. T1: baseline after induction of anesthesia, T2: at the end of nebulization,

T3: 20 minutes after nebulization before cardiopulmonary bypass (CPB), T4: during chest closure after CPB.

ANOVA, analysis of variance; HR, Heart rate; SAP, systemdic arterial pressure; MAP, mean arterial pressure; CVP, central venous pressure; PCWP, pulmonary capillary wedge pressure; SPAP, systolic pulmonary arterial pressure; PAP, diastolic pulmonary arterial pressure; MPAP, mean pulmonary arterial pressure; CO, cardiac output; SVR, systemic vascular resistance; PVR, pulmonary vascular resistance.

${ }^{1} \mathrm{HR}$ increase in the milrinone group in T4 compared to T1 and T2 and in T3 compared withT2

${ }^{2} \mathrm{CVP}$ in the control group became higher at T4 compared to T2

${ }^{3}$ SPAP in the control group lower at T3 compared to T2; ${ }^{4}$ DPAP in the control group lower at T3 compared to T2

${ }^{5} \mathrm{CO}$ in the control group lower at T3 compared to T2 and higher at T4 compared with T1,T2, T3

${ }^{6}$ SVR decrease in the milrinone group at T3 compared to T1 and T4 compared to T1 and T2

${ }^{7} \mathrm{PVR}$ in the control group increase at T2 and T3 compared with T1 and decrease at T4 compared with T3

${ }^{8} \mathrm{PVR}$ in the milrinone group became lower at T4 compared to T2 

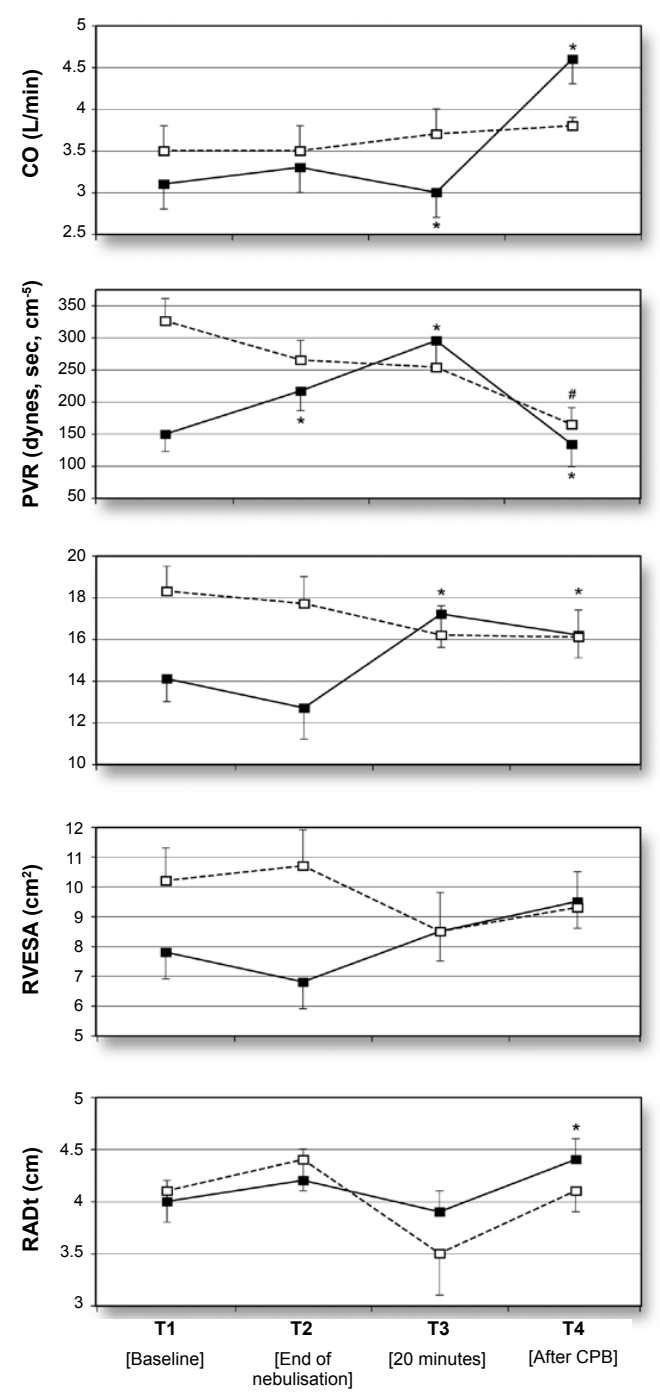

Figure 1: Hemodynamic and echocardiographic changes

Graphical display of changes in cardiac output (CO), pulmonary vascular resistance (PVR), right ventricular end-diastolic area (RVEDA), right ventricular end-systolic area (RVESA) and the right atrial transverse diameter (RADt). $\left(^{*}=p<0.05\right.$ for the control group and \# for the iMil group, see text for details)
The iMil group required less intravenous milrinone (18\% vs. $40 \%$ ), no adrenaline after CPB and no intra-aortic balloon pump. One death occurred in the iMil group and two in the control group. The need for vasopressors for more than 24 hours, the prevalence of atrial fibrillation, ICU and hospital stay durations were similar. An example of the effect of milrinone on two patients is illustrated in Figure 2.

\section{Discussion}

This is the first randomized controlled double-blind trial on the use and safety of iMil in cardiac surgery in which both simultaneous hemodynamic and echocardiographic measurements were obtained. The administration of iMil in this high-risk population was not associated with any significant systemic hypotension compared to the control group. Furthermore, compared with a control group, we observed in the iMil group a modest reduction in the hemodynamic severity of pulmonary hypertension with unaltered ventricular dimensions consistent with a reduction or prevention of the increase in RV afterload. These hemodynamic effects of iMil are consistent with previous observations in animal $[10,11]$ and human studies $[16,17,28]$.

In our patients, before induction and at baseline, the iMil group had much more severe pulmonary hypertension with associated increased right-sided dimensions. Despite this unfavorable condition, no significant systemic hypotension was observed; only 2 patients (18\%) required inotropes, and none returned on $\mathrm{CPB}$ or needed IABP to be weaned from CPB. Furthermore, reduction in right-sided chambers with reciprocal increase in LV dimensions appeared in the iMil group when compared to the control group. These changes could be explained by a reduction in RV afterload by iMil, leading to an increase in pulmonary flow. This would explain the maintenance of LV filling pressure (higher PCWP and DPAP) at 20 minutes after nebulization.

Milrinone is a cyclic AMP-specific phosphodiestersase inhibitor that can exert both positive inotropic effects and vasodilation independently of $B_{1}$-adrenergic receptor stimulation in the cardiovascular system $[23,32]$. Previous studies evaluating the use of intravenous milrinone in cardiac surgical patients were underpowered and performed on a small number of patients undergoing coronary revascularization [33]. Although milrinone has been shown to increase $\mathrm{CO}$ (34-36) and to facilitate separation from $\mathrm{CPB}$ [37], the major problem encountered with intravenous milrinone is the high incidence of systemic hypotension resulting in an increased need for vasoactive drugs $[3,35,38,39]$. The hypotension resulting from intravenous milrinone is either caused by vasodilation or through dynamic left or right ventricular outflow
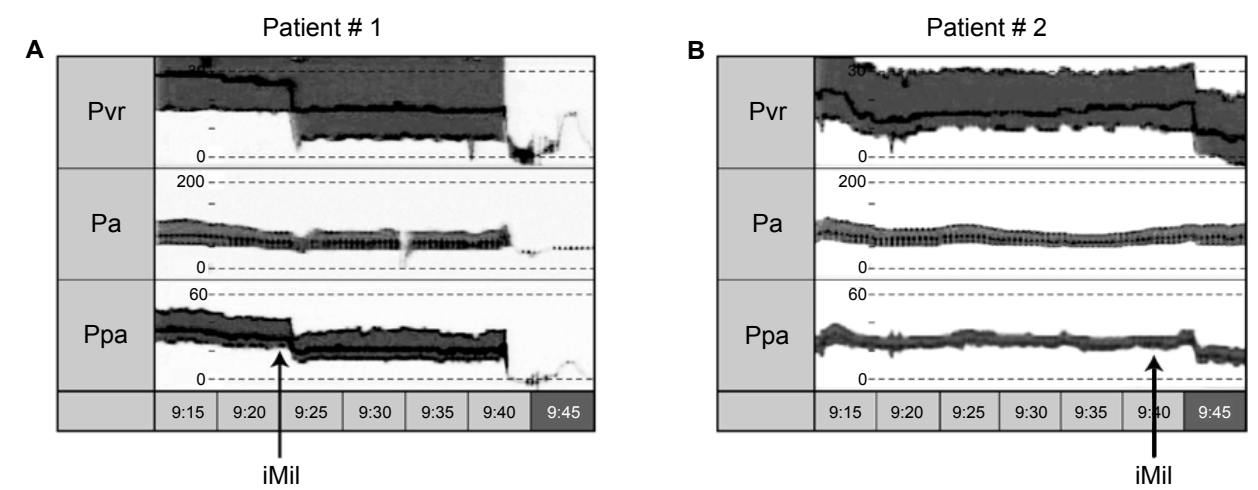

Figure 2: Inhaled milrinone in two patients

Hemodynamic evolution of the right ventricular pressure (Prv), systemic arterial pressure (Pa) and pulmonary artery pressure (Pap) in two patients after receiving inhaled milrinone (iMil) (arrow) before cardiopulmonary bypass. A reduction of the diastolic Prv and Pap without any significant changes in systemic arterial pressure $(\mathrm{Pa})$ is observed. 
Citation: Denault AY, Haddad F, Lamarche Y, Nguyen AQN, Varin F, et al. (2014) Pilot Randomized Controlled Trial of Inhaled Milrinone in High-Risk Cardiac Surgical Patients. Surgery Curr Res 4: 192. doi:10.4172/2161-1076.1000192

Page 6 of 8

\begin{tabular}{|c|c|c|c|c|c|c|c|}
\hline Variables* & Group & $\begin{array}{c}\text { T2 } \\
\text { (End Nebulization) }\end{array}$ & $P$ value & $\begin{array}{c}\text { T3 } \\
\text { (20 minutes) }\end{array}$ & $P$ value & $\begin{array}{c}\mathrm{T} 4 \\
\text { (After CPB) }\end{array}$ & $P$ value \\
\hline \multicolumn{8}{|l|}{ Hemodynamic } \\
\hline \multirow[t]{2}{*}{ PCWP (mmHg) } & Control & $20.5 \pm 1.5$ & 0.2539 & $16.6 \pm 1.8$ & 0.0182 & $22.3 \pm 1.7$ & 0.6198 \\
\hline & Inhaled milrinone & $22.8 \pm 1.3$ & & $22.7 \pm 1.3$ & & $23.5 \pm 1.6$ & \\
\hline \multirow[t]{2}{*}{ DPAP } & Control & $24 \pm 1.0$ & 0.4636 & $21 \pm 0.9$ & $0.0479^{1}$ & $26.7 \pm 3.0$ & 0.8447 \\
\hline & Inhaled milrinone & $23.0 \pm 0.97$ & & $23 \pm 1.3$ & & $25.8 \pm 3.0$ & \\
\hline \multirow[t]{2}{*}{$\mathrm{CO}(\mathrm{L} / \mathrm{min})$} & Control & $3.5 \pm 0.1$ & 0.3198 & $3.1 \pm 0.2$ & 0.1992 & $4.6 \pm 0.2$ & 0.0445 \\
\hline & Inhaled milrinone & $3.3 \pm 0.1$ & & $3.5 \pm 0.2$ & & $3.9 \pm 0.2$ & \\
\hline \multirow[t]{2}{*}{ PVR/SVR (\%) } & Control & $21 \pm 4.4$ & 0.3543 & $13.8 \pm 5.2$ & $0.0043^{2}$ & $8.3 \pm 4.1$ & 0.1953 \\
\hline & Inhaled milrinone & $14.4 \pm 3.7$ & & $8.3 \pm 3.5$ & & $17.3 \pm 3.7$ & \\
\hline \multicolumn{8}{|c|}{ Echocardio-graphic } \\
\hline \multirow[t]{2}{*}{ RVEDA 4ch $\left(\mathrm{cm}^{2}\right)$} & Control & $14.0 \pm 1.2$ & 0.4759 & $19.1 \pm 1.1$ & 0.061 & $17.3 \pm 0.7$ & 0.0023 \\
\hline & Inhaled milrinone & $15.4 \pm 1.3$ & & $14.9 \pm 1.5$ & & $12.7 \pm 0.9$ & \\
\hline \multirow[t]{2}{*}{ RVESA 4ch $\left(\mathrm{cm}^{2}\right)$} & Control & $6.7 \pm 0.8$ & 0.0361 & $9.6 \pm 0.9$ & 0.2917 & $9.8 \pm 0.8$ & 0.0535 \\
\hline & Inhaled milrinone & $10.1 \pm 1.1$ & & $7.9 \pm 1.2$ & & $7.3 \pm 0.9$ & \\
\hline \multirow[t]{2}{*}{ RADt (cm) } & Control & $4.2 \pm 0.2$ & $0.0367^{3}$ & $4.1 \pm 0.1$ & 0.0905 & $4.3 \pm 0.2$ & 0.2129 \\
\hline & Inhaled milrinone & $4.4 \pm 0.2$ & & $3.5 \pm 0.2$ & & $3.8 \pm 0.3$ & \\
\hline \multirow[t]{2}{*}{ LVESA_sax $\left(\mathrm{cm}^{2}\right)$} & Control & $14 \pm 0.7$ & 0.5223 & $11.9 \pm 0.29$ & $0.0106^{5}$ & $13.3 \pm 1.2$ & 0.6105 \\
\hline & Inhaled milrinone & $15 \pm 1.2$ & & $14.1 \pm 0.4$ & & $12.1 \pm 1.9$ & \\
\hline \multirow[t]{2}{*}{ RVFAC (\%) } & Control & $50.7 \pm 3.1$ & $0.0366^{4}$ & $49.5 \pm 4$ & 0.9662 & $41.7 \pm 3.9$ & 0.5458 \\
\hline & Inhaled milrinone & $39 \pm 2.9$ & & $49.2 \pm 5.6$ & & $45.5 \pm 4.7$ & \\
\hline
\end{tabular}

Table 3: One-way ANCOVA adjusted for T1 at separate time interval

*Variables expressed as adjusted mean \pm standard error. Only significant variables are presented. T1: baseline after induction of anesthesia, T2: at the end of nebulization, T3: 20 minutes after nebulization before cardiopulmonary bypass (CPB), T4: during chest closure after CPB. ANCOVA, analysis of covariance; PCWP, pulmonary capillary wedge pressure; DPAP, diastolic pulmonary arterial pressure; CO, cardiac output; PVR/SVR, pulmonary to systemic vascular resistance ratio; RVEDA, right ventricular end-diastolic area; RVESA, right ventricular end-systolic area; RADt, right atrial transverse diameter; LVESA sax, left ventricular short axis view from a mid-papillary transgastric view; RVFAC, right ventricular fractional area.

${ }^{1}$ DPAP had a tendency to be higher at T3 $(p=0.0639)$ in the upper quartile group of the inhaled milrinone group

2 PVR/SVR ratio was higher in the control group in the lower quartile $(p=0.0043)$;

${ }^{3}$ RADt: Control group was smaller at T2 in the lower quartile $(p=0.0437)$

${ }^{4}$ RVFAC was higher in the control group in the lower $(p=0.0056)$ and middle quartile $(p=0.0182)$

${ }^{5}$ LVESA_sax was lower in the control group for the middle $(p=0.0373)$ and higher quartile $(p=0.0130)$

\begin{tabular}{|l|c|c|}
\hline & Control $(n=10)$ & $\begin{array}{c}\text { Inhaled Milrinone } \\
(n=11)\end{array}$ \\
\hline Difficult separation from CPB & $7(70 \%)$ & $7(64 \%)$ \\
\hline Intravenous milrinone post-CPB & $4(40 \%)$ & $2(18 \%)$ \\
\hline Intravenous adrenaline post-CPB & $1(10 \%)$ & 0 \\
\hline Intra-aortic balloon pump requirement & $1(10 \%)$ & 0 \\
\hline Vasopressors use > 24 hours & $4(40 \%)$ & $5(45 \%)$ \\
\hline Atrial fibrillation & $5(50 \%)$ & $6(55 \%)$ \\
\hline Death & $2(20 \%)$ & $1(9 \%)$ \\
\hline ICU stay (hours) & $45(27-96)$ & $72(45-120)$ \\
\hline Hospital stay (days) & $6(5-13)$ & $13(6-23)$ \\
\hline
\end{tabular}

Variables expressed as number (\%) or as mean with 1st and 3rd interquartile range. $\mathrm{CPB}$, cardiopulmonary bypass; ICU, intensive care unit.

Table 4: Outcome data.

tract obstruction [40]. Two randomized controlled trials on the use of milrinone in a non-cardiac surgical setting showed no advantage in terms of hospitalization duration [7,41]. Furthermore, patients receiving milrinone had more adverse events and higher mortality in the PROMISE trial [41]. So far, randomized controlled trials in cardiac surgery have not been designed, or sufficiently powered, to correlate mortality with intravenous milrinone, but the same issue could be encountered. Therefore, it appears relevant to explore alternative strategies such as iMil, which could reduce the severity of pulmonary

hypertension without causing systemic hypotension. However, the first step was to document the absence of significant systemic hypotension in patients receiving iMil.

So far 229 patients have been reported being exposed to iMil in small unblinded trials $[16,17,19,21,22,25]$, retrospective analysis [18] and case reports $[23,24,26,42,43]$. The effect of iMil was first described by Haraldsson et al. [16] in an open-label trial of 20 cardiac surgical patients in the intensive care unit. The first part of the trial included 9 patients and showed a dose-response effect of incremental concentrations of iMil with decreases in MPAP, PVR and PVR/SVR. No patient presented systemic hypotension. The hemodynamic parameters of patients treated with iMil returned to baseline within 20 minutes of the end of the inhalation period, similar to our observation. In the second study [17], iMil was given to 18 heart transplant candidates in the intensive care unit. The MPAP, transpulmonary gradient and PVR decreased only in patients with pulmonary hypertension, defined as MPAP above $30 \mathrm{mmHg}$. Improvement in $\mathrm{CO}$ was observed, but there was no systemic hypotension. The dosage was $2 \mathrm{mg}$ based on intravenous milrinone loading doses used in heart transplantation, which was almost half of the dose used in our protocol. In these studies, there was no control group, and the intraoperative usage and the timing of iMil in relation to $\mathrm{CPB}$ were not recorded. We have previously described the administration of iMil before CPB in 40 highrisk patients with a Parsonnet score of $30.4 \pm 14.2$ [28]. Compared 
to the administration of iMil after $\mathrm{CPB}$, pre-CPB iMil was associated with a reduction of difficult separation from CPB (18\% vs. 82\%) defined as the use of more than two inotropes, need for introduction of an intra-aortic balloon pump or reinitiation of CPB. Finally a recent study compared the use of intravenous versus inhaled milrinone in 48 patients with pulmonary hypertension after mitral valve surgery [19]. With milrinone administration, mean pulmonary artery pressure and pulmonary vascular resistance decreased in both groups. However, the mean arterial pressure and systemic vascular resistance in the inhaled group were significantly higher than in the intravenous group. In addition, in the inhaled group, there was a reduction in intrapulmonary shunt fraction in the inhaled milrinone group.

In the current study, the same ratio was observed; 4 patients in the control group compared to 1 in the iMil group would have qualified for this definition. Significantly lower SPAP and unchanged LV function were also observed after CPB in the group who received iMil pre-CPB, as observed in the current study, but RV function was not analyzed. Finally a recent study compared the use of intravenous versus inhaled milrinone in 48 patients with pulmonary hypertension after mitral valve surgery [19] . With milrinone administration, mean pulmonary artery pressure and pulmonary vascular resistance decreased in both groups. However, the mean arterial pressure and systemic vascular resistance in the inhaled group were significantly higher than in the intravenous group. In addition, in the inhaled group, there was a reduction in intrapulmonary shunt fraction in the inhaled milrinone group.

Administration of iMil before CPB could be advantageous for several reasons. First, iMil could protect the pulmonary vasculature during weaning from $\mathrm{CPB}$ when ischemia-reperfusion injury occurs through a more uniform distribution and penetration in mechanically ventilated lungs free of significant post-CPB atelectasis [10]. This may explain why patients receiving iMil before $\mathrm{CPB}$ were found to have lower or similar MPAP after separation from CPB [28]. These findings were not observed when intravenous milrinone [10] was administered or when the administration of the drug occurred after CPB [28]. Secondly, the administration of iMil before CPB could prevent the reperfusion syndrome [44].

\section{Limitations}

There are several study limitations that need to be addressed. The number of patients is small. It was important for us to determine the safety of iMil given intraoperatively in patients under general anesthesia because it had not been studied in this context previously. Before the induction and at baseline before drug administration, the iMil patients had more severe pulmonary hypertension. Therefore, after presenting the observed values and performing the same analysis as originally published by Haraldsson and Sablotzki [16,17], we compared both groups using two-way ANCOVA with adjusted values. Despite the small number of patients, we observed differences in PVR/SVR and RV dimensions between the groups consistent with a RV afterload effect of iMil. The absolute effect of iMil on the severity of pulmonary hypertension was modest but similar to that described in previous observational studies [16,17]. The number of patients was too small to explore other significant outcomes such as length of intensive care unit stay, hospitalization duration and mortality. However, this study was the necessary step to confirm our animal and preliminary human observations and the safety of this new strategy. Finally, systemic exposition to milrinone was not documented in these patients. We have previously reported that milrinone concentration obtained in cardiac patients having the same characteristics are below $30 \mathrm{ng} / \mathrm{mL}$ when milrinone is given by inhalation [45].Milrinone levels below $100 \mathrm{ng} /$
$\mathrm{mL}$ are not likely to induce significant systemic hypotension in cardiac patients [46].

\section{Conclusion}

In summary, the administration of iMil before initiation of CPB is not associated with any significant systemic hypotension. In patients receiving iMil, we observed a mild reduction in the severity of pulmonary hypertension with improved right-sided cavity dimensions compared to the control group. Further studies with larger numbers of patients are required to document the potential benefit of this approach in the care of cardiac surgical patients with pulmonary hypertension.

\section{Acknowledgement}

Supported by the Montreal Heart Institute Research Foundation, the Fonds de la recherche en santé du Québec and the Canadian Heart and Stroke Foundation.

\section{References}

1. Bernstein $A D$, Parsonnet $V(2000)$ Bedside estimation of risk as an aid for decision-making in cardiac surgery. Ann Thorac Surg 69: 823-828.

2. Vincens JJ, Temizer D, Post JR, Edmunds LH Jr, Herrmann HC (1995) Longterm outcome of cardiac surgery in patients with mitral stenosis and severe pulmonary hypertension. Circulation 92: II137-142.

3. Solina A, Papp D, Ginsberg S, Krause T, Grubb W, et al. (2000) A comparison of inhaled nitric oxide and milrinone for the treatment of pulmonary hypertension in adult cardiac surgery patients. J Cardiothorac Vasc Anesth 14: 12-17.

4. Feneck RO, Sherry KM, Withington PS, Oduro-Dominah A; European Milrinone Multicenter Trial Group (2001) Comparison of the hemodynamic effects of milrinone with dobutamine in patients after cardiac surgery. J Cardiothorac Vasc Anesth 15: 306-315.

5. Couture P, Denault AY, Pellerin M, Tardif JC (2007) Milrinone enhances systolic but not diastolic function during coronary artery bypass grafting surgery. Can $\mathrm{J}$ Anaesth 54: 509-522.

6. Jaski BE, Fifer MA, Wright RF, Braunwald E, Colucci WS (1985) Positive inotropic and vasodilator actions of milrinone in patients with severe congestive heart failure. Dose-response relationships and comparison to nitroprusside. J Clin Invest 75: 643-649.

7. Cuffe MS,Califf RM, Adams KF Jr, Benza R, Bourge R, et al. (2002) Shortterm intravenous milrinone for acute exacerbation of chronic heart failure: a randomized controlled trial. JAMA 287: 1541-1547.

8. Felker GM, Benza RL, Chandler AB, Leimberger JD, Cuffe MS, et al. (2003) Heart failure etiology and response to milrinone in decompensated hear failure: results from the OPTIME-CHF study. J Am Coll Cardiol 41: 997-1003.

9. Gelvez J, Fakioglu H, Olarte JL, Soliz A, Totapally BR, et al. (2004) Effect of aerosolized milrinone during drug-induced pulmonary hypertension in lambs. Pharmacol Res 50: 87-91.

10. Lamarche Y, Malo O, Thorin E, Denault AY, Carrier M, Roy J, et al. (2005) Inhaled but not intravenous milrinone prevents pulmonary endothelial dysfunction after cardiopulmonary bypass. J Thorac Cardiovasc Surg: 83-92.

11. Hentschel T, Yin N, Riad A, Habbazettl H, Weimann J, et al. (2007) Inhalation of the phosphodiesterase-3 inhibitor milrinone attenuates pulmonary hypertension in a rat model of congestive heart failure. Anesthesiology 106: 124-131.

12. Chen F, Zhang J, Aoyama A, Okamoto T, Fujinaga T, et al. (2008) Potential for pulmonary protection by nebulized milrinone during warm ischemia. Transplant Proc 40: 3335-3338.

13. Zhang , Chen F, Zhao X, Aoyama A, Okamoto T, et al. (2009) Nebulized phosphodiesterase III inhibitor during warm ischemia attenuates pulmonary ischemia-reperfusion injury. J Heart Lung Transplant 28: 79-84.

14. Bueltmann M, Kong X, Mertens M, Yin N, Yin J, et al. (2009) Inhaled milrinone attenuates experimental acute lung injury. Intensive Care Med 35: 171-178.

15. Kumar VH, Swartz DD, Rashid N, Lakshminrusimha S, Ma C, et al. (2010) Prostacyclin and milrinone by aerosolization improve pulmonary hemodynamics in newborn lambs with experimental pulmonary hypertension. J Appl Physiol (1985) 109: 677-684

16. Haraldsson A, Kieler-Jensen N, Ricksten SE (2001) The additive pulmonary vasodilatory effects of inhaled prostacyclin and inhaled milrinone in postcardiac surgical patients with pulmonary hypertension. Anesth Analg :1439-1445. 
Citation: Denault AY, Haddad F, Lamarche Y, Nguyen AQN, Varin F, et al. (2014) Pilot Randomized Controlled Trial of Inhaled Milrinone in High-Risk Cardiac Surgical Patients. Surgery Curr Res 4: 192. doi:10.4172/2161-1076.1000192

17. Sablotzki A, Starzmann W, Scheubel R, Grond S, Czeslick EG (2005) Selective pulmonary vasodilation with inhaled aerosolized milrinone in heart transplant candidates Can J Anaesth: 1076-1082.

18. Lamarche Y, Perrault LP, Maltais S, Tétreault K, Lambert J, et al. (2007) Preliminary experience with inhaled milrinone in cardiac surgery. Eur $\mathrm{J}$ Cardiothorac Surg 31: 1081-1087.

19. Wang H, Gong M, Zhou B, Dai A (2009) Comparison of inhaled and intravenous milrinone in patients with pulmonary hypertension undergoing mitral valve surgery. Adv Ther 26: 462-468.

20. Hegazy N (2010)Comparison of hemodynamic effects of inhaled milrinone and inhaled prostacyclin after adult cardiac surgery. Journal of Applied Science Research: 38-44

21. Singh R, Choudhury M, Saxena A, Kapoor PM, Juneja R, et al. (2010). Inhaled Nitroglycerin Versus Inhaled Milrinone in Children with Congenital Heart Disease Suffering from Pulmonary Artery Hypertension. J Cardiothorac Vasc Anesth Jan 5.

22. Gong M, Lin XZ, Lu GT, Zheng LJ (2012) Preoperative inhalation of milrinone attenuates inflammation in patients undergoing cardiac surgery with cardiopulmonary bypass. Med Princ Pract 21: 30-35

23. Denault AY, Lamarche $Y$, Couture P, Haddad F, Lambert J, et al. (2006) Inhaled milrinone: a new alternative in cardiac surgery? Semin Cardiothorac Vasc Anesth 10: 346-360.

24. Buckley MS, Feldman JP (2007) Nebulized milrinone use in a pulmonary hypertensive crisis. Pharmacotherapy 27: 1763-1766

25. Carev M, Bulat C, KaranoviÄ $¥$, Lojpur M, JerciÄ $\ddagger$, et al. (2010) Combined usage of inhaled and intravenous milrinone in pulmonary hypertension after heart valve surgery. Coll Antropol 34: 1113-1117.

26. St-Pierre P, Deschamps A, Cartier R, Basmadjian A, Denault AY (2013) Inhaled milrinone and epoprostenol in a patient with severe pulmonary hypertension, right ventricular failure and reduced baseline brain saturation value from a left atrial myxoma. J Cardiothorac Vasc Anesth (In press).

27. Beaulieu Y, Denault AY, Couture P, Roy D, Talajic M, et al. (2010) Perioperative intravenous amiodarone does not reduce the burden of atrial fibrillation in patients undergoing cardiac valvular surgery. Anesthesiology 112: 128-137.

28. Lamarche Y, Perrault LP, Maltais S, Tétreault K, Lambert J, et al. (2007) Preliminary experience with inhaled milrinone in cardiac surgery. Eur $J$ Cardiothorac Surg 31: 1081-1087.

29. Schnittger I, Fitzgerald PJ, Daughters GT, Ingels NB, Kantrowitz NE, et al (1982) Limitations of comparing left ventricular volumes by two dimensional echocardiography, myocardial markers and cineangiography. Am J Cardiol 50 : $512-519$

30. Lang RM, Bierig M, Devereux RB, Flachskampf FA, Foster E, Pellikka PA et al. (2005) Recommendations for chamber quantification: a report from the American Society of Echocardiography's Guidelines and Standards Committee and the Chamber Quantification Writing Group, developed in conjunction with the European Association of Echocardiography, a branch of the European Society of Cardiology. J Am Soc Echocardiogr: 1440-1463.

31. Costachescu T, Denault A, Guimond JG, Couture P, Carignan S, et al. (2002) The hemodynamically unstable patient in the intensive care unit: hemodynamic vs. transesophageal echocardiographic monitoring. Crit Care Med 30: 1214 1223.

32. Baim DS, McDowell AV, Cherniles J, Monrad ES, Parker JA, et al. (1983) Evaluation of a new bipyridine inotropic agent--milrinone--in patients with severe congestive heart failure. N Engl J Med 309: 748-756.
33. Omae T, Kakihana Y, Mastunaga A, Tsuneyoshi I, Kawasaki K, Kanmura Y, et al. (2005)Hemodynamic changes during off-pump coronary artery bypass anastomosis in patients with coexisting mitral regurgitation: improvement with milrinone. Anesth Analg: 2-8.

34. Kikura M, Levy JH, Michelsen LG, Shanewise JS, Bailey JM, et al. (1997) The effect of milrinone on hemodynamics and left ventricular function after emergence from cardiopulmonary bypass. Anesth Analg 85: 16-22.

35. Lobato EB, Florete O Jr, Bingham HL (1998) A single dose of milrinone facilitates separation from cardiopulmonary bypass in patients with pre-existing left ventricular dysfunction. $\mathrm{Br} \mathrm{J}$ Anaesth 81: 782-784.

36. Iwagaki T1, Irie J, ljichi K, Uratsuji Y (2001) [The effects of milrinone on hemodynamics in patients undergoing cardiac surgery]. Masui 50: 360-364.

37. Doolan LA, Jones EF, Kalman J, Buxton BF, Tonkin AM (1997) A placebocontrolled trial verifying the efficacy of milrinone in weaning high-risk patients from cardiopulmonary bypass. J Cardiothorac Vasc Anesth 11: 37-41.

38. Yamada T, Takeda J, Katori N, Tsuzaki K, Ochiai R (2000) Hemodynamic effects of milrinone during weaning from cardiopulmonary bypass: comparison of patients with a low and high prebypass cardiac index. J Cardiothorac Vasc Anesth 14: 367-373.

39. Kim JH, Ham BM, Kim YL, Bahk JH, Ryu HG, et al. (2003) Prophylactic milrinone during $O P C A B$ of posterior vessels: implication in angina patients taking beta-blockers. Eur J Cardiothorac Surg 24: 770-776.

40. Denault AY, Chaput M, Couture P, Hébert Y, Haddad F, et al. (2006) Dynamic right ventricular outflow tract obstruction in cardiac surgery. J Thorac Cardiovasc Surg 132: 43-49.

41. Packer M, Carver JR, Rodeheffer RJ, Ivanhoe RJ, DiBianco R, et al. (1991) Effect of oral milrinone on mortality in severe chronic heart failure. The PROMISE Study Research Group. N Engl J Med 325: 1468-1475.

42. Nguyen $A Q$, Théorêt $Y$, Chen $C$, Denault $A$, Varin $F$ (2009) High performance liquid chromatography using UV detection for the quantification of milrinone in plasma: improved sensitivity for inhalation. J Chromatogr B Analyt Technol Biomed Life Sci 877: 657-660.

43. Denault AY, Haddad F, Jacobsohn E, Deschamps A (2013) Perioperative right ventricular dysfunction. Curr Opin Anaesthesiol 26: 71-81.

44. Lesage AM, Tsuchioka H, Young WG Jr, Sealy WC (1966) Pathogenesis of pulmonary damage during extracorporeal perfusion. Arch Surg 93: 1002-1008.

45. Nguyen AQ, Théorêt $Y$, Chen $C$, Denault A, Varin F (2009) High performance liquid chromatography using UV detection for the quantification of milrinone in plasma: improved sensitivity for inhalation. J Chromatogr B Analyt Techno Biomed Life Sci 877: 657-660.

46. Woolfrey SG, Hegbrant J, Thysell H, Fox PA, Lendrem DW, et al. (1995) Dose regimen adjustment for milrinone in congestive heart failure patients with moderate and severe renal failure. J Pharm Pharmacol 47: 651-655. 